\title{
Evaluating the Long-Term Effectiveness of the SGA Enhanced Services Model in Kentucky: A Follow-Up Study on the SGA Demonstration Project
}

\author{
Kellie Scott ${ }^{1 \text { a }}$ \\ 1 Kentucky Office of Vocational Rehabilitation \\ Keywords: ssdi, employment, vocational rehabilitation \\ https://doi.org/10.52017/001c.26136
}

\section{Rehabilitation Counselors and Educators Journal}

Vol. 10, Issue 2, 2021

\begin{abstract}
During federal fiscal year (FY) 2016 and 2017, the Kentucky Office of Vocational Rehabilitation (KY OVR) implemented the Substantial Gainful Activity (SGA) Project, providing enhanced services to Social Security Disability Insurance (SSDI) recipients who also applied for services through the general Vocational Rehabilitation (VR) agency. Short-term evaluative efforts revealed that consumers receiving enhanced services were more likely to be competitively employed, achieving slightly higher earnings and in a shorter period. This longer-term follow-up study indicated promising results, noting sustained differences in wages and time to employment. Higher wages and a faster path to employment can positively impact the economic outcomes of individuals receiving SSDI benefits through innovative VR service and support models.
\end{abstract}

\section{Background and Purpose}

The federal Social Security Disability Insurance (SSDI) program provides income support for working-age people with disabilities who have been determined eligible and have a prior work history (Social Security Administration [SSA], n.d.). While participation in the program has nearly doubled in recent years, and an array of work incentives encouraging return to work have been added, the return-towork rate of approximately $15 \%$ for this population remains low (Ben-Shalom \& Mamun, 2013; Mamun et al., 2011). Substantial gainful activity (SGA) is the earnings amount used by SSA to assess whether an individual remains eligible for ongoing access to the SSDI program.

Kentucky Office of Vocational Rehabilitation (KY OVR) participated in the original Substantial Gainful Activity (SGA) Demonstration Project, which used a randomized control design and involved four key service interventions delivered by a three-member team (Martin \& Sevak, 2020; Sevak et al., 2017). The model provided early benefits counseling and financial planning, early job placement, and an overall faster pace of VR service delivery using a coordinated team approach (CTA) consisting of the Vocational Rehabilitation Counselor (VRC), Kentucky Work Incentives Coordinator (KWIC), and a Job Placement Specialist (JPS). The team had a goal to initially meet with the consumer within five days of eligibility determination and periodically thereafter. The VR counselors at the enhanced-service sites also aimed to complete eligibility determination within two days, and Individualized Plans for Employment (IPEs) within 30 days. Comparatively, the federally-required eligibility determination period can take up to 60 days and IPEs are developed within 90 days of eligibility determination. Second, financial education and benefits planning was provided to all consumers in the enhanced-service sites. KWICs were hired and housed at KY OVR to provide these services. The third component was early involvement of job placement services. Three JPSs were hired to assist current VR staff to ensure job placement was provided to consumers beginning at application. Findings from the initial SGA Project indicated that KY OVR staff accepted faster pacing as a best practice when they observed clients were more engaged. The Kentucky VR agency had two full years of Unemployment Insurance (UI) data available following the completion of the SGA project, and was interested to learn whether the improved outcomes continued for the treatment group participants.

Additionally, due to the improved outcomes achieved through the SGA Project, the VR agency invested resources into hiring more job placement and work incentive staff members. These services were expanded to serve all $\mathrm{KY}$ OVR consumers at the end of the project; therefore, it is important to evaluate long-term effects of these investments. Furthermore, following completion of the SGA Project, KY OVR invested in expanding Motivational Interviewing training from just those serving treatment group participants to all VR counselors in the agency.

The purpose of this evaluation was to assess whether the SGA Project in Kentucky made a positive lasting impact on KY OVR consumers receiving SSDI benefits. The evalu- 
Table 1. Wage Comparisons Between Treatment and Control Groups

\begin{tabular}{lcc}
\hline \multicolumn{1}{c}{ Wage information } & $\begin{array}{c}\text { Treatment group } \\
(\mathrm{N}=536)\end{array}$ & $\begin{array}{c}\text { Control group } \\
(\mathrm{N}=520)\end{array}$ \\
\hline \# with any earned income & 245 & 223 \\
\% with any earned income & $45.7 \%$ & $42.9 \%$ \\
Average annual earned income of those employed & $\$ 10,602.02$ & $\$ 8,152.39$ \\
\# at or above SGA (\$1,220/month) for 2 years & 22 & 7 \\
\% at or above SGA $(\$ 1,220 /$ month) for 2 years & $9 \%$ & $3.1 \%$ \\
\hline
\end{tabular}

ation questions addressed were: (a) did enhanced services group participants continue to earn higher wages?; (b) did enhanced services group participants achieve a faster return to the workforce; and (c) was the dropout rate of VR services before achieving employment reduced for enhanced services group participants?

\section{Methods}

Data from the KY OVR case management system (CMS) was used to assess the number of days to employment and employment status, as suggested by Sevak and colleagues (2017). UI data was used to measure work outcomes. Kentucky OVR has a data sharing agreement with the state's UI program and wage data was imported into the KY OVR data reports system and cross referenced with KY OVR cases using Social Security numbers as unique identifiers. T-test analyses were conducted using the VR Program Evaluation Coach (https://www.mathematica.org/products/vr-program-evaluation-coach) to analyze the data based on treatment and control group assignment in the prior SGA Project. This analysis included a total of 1,056 participants, randomly assigned into treatment $(\mathrm{N}=536)$ and control $(\mathrm{N}$ $=520$ ) groups.

\section{Results}

Analysis of the UI data indicated that consumers in the enhanced services were (a) more likely to be employed, (b) more likely to earn higher wages, and (c) were more likely to be employed above SGA level two years following completion of the original project (see Table 1). Furthermore, analysis of the KY OVR case management system (i.e., state VR) data indicated that consumers in the enhanced services group were (a) employed in a faster period of time, (b) more likely to be employed, and (c) more likely to be employed above SGA level when compared with the control group.

Specifically, the enhanced services group experienced an average of more than $\$ 200$ more in monthly wages, and those with income were more than twice as likely to be earning at or above SGA levels longer-term. And finally, enhanced services group participants achieved successful employment outcomes more than 2.5 months faster than control group participants, and were $33 \%$ more likely to be employed at the time of case closure.

\section{Recommendations and Implications for Practice}

Findings from both the original SGA Project and our fol- low-up evaluation indicated an increase in successful employment and earnings outcomes for SSDI beneficiaries receiving enhanced services through KY OVR. Given these promising results, state VR programs are encouraged to consider adopting a similar approach to enhance early engagement and improve outcomes with this population. Further evaluation and research recommendations include conducting return-on-investment studies to better understand costs and benefits for VR programs when considering investments in additional staff and positions, work incentives benefits counseling tools (e.g., Disability Benefits 101), and Motivational Interviewing training.

Additionally, the VR Program Evaluation Coach developed by Mathematica was a valuable resource to use when analyzing the data. This tool supported a scientific approach to analyses and helped us better understand the data and findings, beyond solely consumer location or demographics. An ancillary benefit of this project was the ability to collaborate with national evaluators and technical assistance providers. By collaborating with multiple organizations, we learned that the VR agency could remain focused on consumer services, while the partners remained focused on the technical support and external evaluation of the project leading to overall project success. As the saying goes "We are better together." The following recommendations and lessons learned are offered for other VR colleagues to consider in their practice:

- Provide faster pacing and/or utilize Motivational Interviewing (MI) to enhance engagement.

- Utilize dynamic Individual Plan for Employment (IPE) methods and train staff on their use.

- Provide job placement and benefits analysis earlier in the VR process with continued follow-up. DB101 (or a similar online tool) and Work Incentives Planning and Assistance (WIPA) can be used to enhance these ongoing services. Partner with other agencies to accomplish this task.

- Provide services using a coordinated team approach and allow for meeting online, if and when necessary.

\section{Author Note}

The contents of this paper were developed under a cooperative agreement with the U.S. Department of Education, Technical Assistance Center for Vocational Rehabilitation Agency Program Evaluation and Quality Assurance 
(PEQA-TAC) (Grant Award Number: H263B150004). However, the contents and views expressed in this publication do not necessarily represent the positions or policies of the
U.S. Department of Education, and you should not assume endorsement by the Federal government. 


\section{References}

Ben-Shalom, Y., \& Mamun, A. F. (2013). Return-to-work outcomes among Social Security Disability Insurance program beneficiaries. Mathematica Policy Research. $\underline{\mathrm{h}}$ ttps://www.mathematica.org/publications/returntow ork-outcomes-among-social-security-disability-insur ance-program-beneficiaries

Mamun, A. A., O’Leary, P., Wittenburg, D. C., \& Gregory, J. (2011). Employment among Social Security Disability Program beneficiaries, 1996-2007. Social Security Bulletin, 71(3), 11-34.
Martin, F., \& Sevak, P. (2020). Implementation and impacts of the Substantial Gainful Activity Project demonstration in Kentucky. Journal of Vocational Rehabilitation, 53(3), 297-305. https://doi.org/10.323 3/IVR-201106

Sevak, P., Martin, F., Livermore, G., Honeycutt, T., \& Morris, E. (2017). Kentucky Substantial Gainful Activity (SGA) Project demonstration: Final evaluation report. Mathematica Policy Research. http s://www.explorevr.org/returntoworkssdi/what-is-sga

Social Security Administration. (n.d.). Substantial gainful activity. Retrieved July 13, 2021, from https://www.ss a.gov/oact/cola/sga.html 